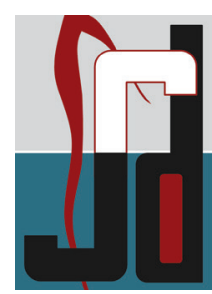

REVIEW

\title{
Immunosuppressant Drugs: Role in Periodontium
}

AnjushaBhadran $^{1}$, Seema.G ${ }^{2}$

\begin{abstract}
The periodontium and periodontal disease activity can be affected by systemic drug therapy. Immunosuppressant drugs are one among such category. These drugs in common, influences the response of gingival and periodontal tissues to bacterial plaque. An extremely effective and most commonly used immunosuppressant drug for organ transplant procedures is cyclosporine A. The drug is also associated with various untoward effects, including gingival overgrowth.Corticosteroids are another major drug category, which may either exert its action as an immunosuppressant or as an anti- inflammatory agent. This review considers the pharmacokinetics, pharmacodynamics, and unwanted effects of immunosuppressants, on the gingival tissues.
\end{abstract}

Key words: Periodontium, Periodontal disease,Immunosuppressants, Cyclosporin A( CsA ), Corticosteroids, Gingival overgrowth.

\section{Introduction}

Periodontal disease is the result of an interaction between bacterial plaque and its products and the resultant inflammatory and immunological changes within the periodontal tissues. 1,2The nature and the pathogenesis of periodontal disease can be affected by a variety of drugs, especially those that interact with immune and inflammatory responses. Hence, such drug therapy can modify the effect of bacterial plaque on the periodontal tissues. In addition, some drugs can have adverse effects on the periodontal tissues such as gingival overgrowth.

The purpose of this review is to investigatethe effect of systemic therapy of immunosuppressantson periodontal tissues, andwhere possible to relate such changesto the pharmacodynamics of the drugsinvolved. Reports from the literaturehave shown that immunosuppressants act on various components of the immune system causing selective inhibition and suppression. Drugs used for this purpose include corticosteroids (mainly prednisone and prednisolone), azathioprine and more recently cyclosporin.

\section{Immunosuppressants}

Immunosuppressant drugs, as their name suggests, are a group of compounds that target the immune system and suppress various aspects of this system. They have three main indications in medicine:
- to suppress rejection in organ-transplant patients.

- in the treatment of a variety of chronic inflammatory conditions, where suppression of the immune response may help to alleviate symptoms.

- in the management of autoimmune diseases.

There are several drugs that can affect the immune system and which have therapeutic applications.

List of immunosuppressants used in medical practice and their indications. ${ }^{3}$ Table 1

\section{Immunosuppressants and the Periodontium}

Early studies, in the 1970s and 1980s, showed that patients on long-term immunosuppressants (usually azathioprine and prednisolone) were afforded some degree of protection againstperiodontal breakdown. The more selective immunosuppressants (cyclosporine and tacrolimus) may not afford the same degree of protection against periodontal breakdown.

However, with cyclosporine, the unwanted effect of gingival overgrowth will inhibitplaque removal and thus create a somewhat different environment for periodontal disease.Animal studies have suggested that cyclosporine can have an adverse effect on alveolar bone homeostasis, resulting in increased osteoclasia and a decrease in bone formation.$^{4}$ 
As with other categories of systemic medication, there is little or no therapeutic indication for the use of immunosuppressants in the management of periodontal disease. As with other anti-inflammatory agents, the main interest in these drugs is what their pharmacodynamics can tell us about the pathogenesisof periodontal disease and periodontal breakdown.Their unwanted effects would exclude any indication for their use in the management of periodontal disease.

\section{AntiproliferativeImmunosuppressants}

The two main examples of this category of immunosuppressants are azathioprine and mycophenolatemofetil.

\section{Azathioprine}

Azathioprine is a purine derivative which can be considered as a prodrug. The drug is first metabolized to 6-mercaptopurine and further metabolized by the enzyme thiopurinemethyltransferase to the pharmacologically active 6-thioguanine nucleotide. The latter suppresses the immune system by inhibiting DNAsynthesis in lymphocytes.

\section{Unwanted Effects}

Increased susceptibility to infections, especially opportunistic infections, and bone marrow suppression. A drug-induced depression of platelets could lead to petechial hemorrhages and also to profuse bleeding from the gingival tissues, especially upon any form of gingival manipulation. A reduction in the white cell count will increase the risk of oral ulceration and periodontal breakdown. Azathioprine-induced myelosuppression is most likely to manifest in the early stages of treatment and is managed by reducing the dose.

\section{MycophenolateMofetil}

Mycophenolatemofetil is considered a prodrug and is hydrolyzed to mycophenolic acid. Mycophenolic acid reduces both $\mathrm{B}$ - and $\mathrm{T}$-cell proliferation by inhibiting the production of guaninenucleotide. It has been suggested that mycophenolatemofetil may be effective against both acute and chronic organrejection. ${ }^{5}$

\section{Unwanted Effects}

The most significant unwanted effectaremyelosuppression andthrombocytopenia.
Patients on this drug will undergo regular haematological screening and if any form of periodontal surgery is planned then a blood test should be requested beforethe procedure, with specific attention given to the platelet count. Also associated with a high prevalence of gastrointestinal problems, especially vomiting. This can readily leadto dental erosion, and preventive measures need tobe put into place to avoid the outcome of thisunwanted effect.

\section{Calcineurin Inhibitors}

Calcineurin is a protein phophatase that activatesTcells of the immune system. It is the target of drugssuch as cyclosporine and tacrolimus.

\section{Cyclosporine}

Cyclosporine has had a dramatic effect on patientsundergoing organ-transplant surgery, on subsequentgraft survival and on quality of life. The main mode ofaction of cyclosporine is its selective inhibitory effecton transcription of the interleukin-2 gene.

- There is decreased clonalproliferation of T-cells.

- Reduced induction of, andclonal proliferation of, cytotoxic cells from CD8+precursor T-cells.

- Reduced function of the effector Tcellsand some reduction in T-cell-dependent B-cellresponses.

\section{Unwanted Effect}

From the periodontal perspective, the main interestin cyclosporine is the unwanted effect of gingivalovergrowth. This was first reported in the early 1980sand has been the subject of extensive research. Otherunwanted effects of cyclosporine include nephrotoxicity,hypertension and an increased risk of skinmalignancies.CsA elicited enlargement and overgrowth of gingiva in human organ transplant recipients. ${ }^{6}$ Recent investigations reported incidence be approximately $25 \%$ to $30 \%$.

\section{Tacrolimus}

Tacrolimus is a macrolide antibiotic that also inhibitscalcineurin. It is more potent than cyclosporine, andis now replacing cyclosporine as the treatment ofchoice to prevent graft rejection in organ transplantation. 


\begin{tabular}{|l|l|}
\hline Immunosuppressant & \multicolumn{1}{|c|}{ Indications } \\
\hline Azathioprine & $\begin{array}{l}\text { Transplant patients, inflammatory bowel disease, } \\
\text { rheumatoid arthritis, severe refractory eczema }\end{array}$ \\
\hline Mycophenolatemofetil & $\begin{array}{l}\text { Prophylaxis of acute renal, hepatic and cardiac transplant } \\
\text { rejection }\end{array}$ \\
\hline Prednisolone & Prevention of graft rejection \\
\hline Cyclosporine & Prevention of graft rejection, treatment of graft-vs.-host \\
disease, severe ulcerative colitis, rheumatoid arthritis, \\
severe skin disorders
\end{tabular}

Table : 1 List of immunosuppressants used in medical practice and their indications

Unwanted effects of tacrolimus includegastrointestinal disturbances, hypertension, nephrotoxicityand metabolic disturbances.

\section{Corticosteroids}

Corticosteroids are a group of drugs that are structurally and pharmacologically related to the

endogenous hormone cortisol. There are several corticosteroids, each with different potencies and applications.

Corticosteroids are extensively used in many aspects of medicine. They can be applied topically, by inhalation, orally and parenterally.

\section{Pharmacological properties}

Therapeutic usage correlates with their antiinflammatory and immunosuppressive actions. Antiinflammatory action is mediated via
- The ability to stimulate the production of a protein known as lipocortin-1 (annexin A1) ${ }^{8}$. Lipocortin suppresses the enzyme phopholipase A2. Thus stimulation of lipocortin, blocks the production of various eicosanoids ( prostaglandins and leukotrienes).

- Also suppress the enzymes cyclooxygenase-1 and cyclooxygenase-2, further reducing eicosanoid synthesis.

A list of those widely prescribed inmedical practice is given in Table 2.

\section{Immunosuppressant action is mediated by:}

- Suppress the cell-mediatedresponse by inhibiting the genes that code for cytokinesinterleukin- 1 to -6 , interleukin- 8 and interferon-c resulting in reduced $\mathrm{T}$-cell proliferation. 


\begin{tabular}{|c|c|}
\hline Corticosteroid & Indication \\
\hline Hydrocortisone & $\begin{array}{l}\text { Adrenocortical insufficiency, shock, hypersensitivity reaction, asthma, } \\
\text { inflammatory bowel disease, skin disorders, rheumatic diseases }\end{array}$ \\
\hline Cortisone acetate & Steroid replacement therapy \\
\hline Betamethasone & $\begin{array}{l}\text { Suppression of inflammatory and allergic disorders, congenital adrenal } \\
\text { hyperplasia, oral ulceration }\end{array}$ \\
\hline Deflazacort & Suppression of inflammatory and allergic disorders \\
\hline Dexamethasone & $\begin{array}{l}\text { Suppression of inflammatory and allergic disorders, cerebral edema, } \\
\text { nausea and vomiting from chemotherapy, rheumatic diseases }\end{array}$ \\
\hline Prednisolone & $\begin{array}{l}\text { Suppression of inflammatory and allergic disorders, asthma, } \\
\text { immunosuppression, rheumatic diseases }\end{array}$ \\
\hline Methylprednisone & $\begin{array}{l}\text { Suppression of inflammatory and allergic disorders, inflammatory } \\
\text { bowel disease, rheumatic diseases }\end{array}$ \\
\hline Triamcinalone & Suppression of inflammatory and allergic disorders, skin conditions \\
\hline
\end{tabular}

Table 2 : A list of those widely prescribed in medical practice is given

- Humoral immunity isalso suppressed, resulting in a reduction in B-cell-cloneexpansion and antibody synthesis and reducedactivation of T-lymphocytes. 9

Combined immunosuppressant and anti- inflammatory actions are mediated by activationof the glucocorticoid receptor. Activated glucocorticoid receptors upregulates the expressionof anti-inflammatory proteins and suppressesthe expression of pro- inflammatory proteins. ${ }^{10}$

\section{Corticosteroids And The Periodontium}

Early animal studies showed that systemic cortisoneinjections have a significant effect on periodontaltissues ${ }^{11}$, including induction of alveolar bone lossand reduction in the numbers of osteoblasts and fibroblastsand of the intercellular matrix. This conditionis identical to the bone status seen inosteoporosis and has been confirmed in further animalstudies, which demonstrated that anti-osteoporoticdrugs (calcitonin and alendronate) preventedcorticosteroid-induced osteoporosis. ${ }^{12}$ Other animalstudies also showed that systemic cortisonecould attenuate the plaque-induced inflammatoryresponses in the periodontal tissues.

Human studies on patients on long-term steroid therapyfor medical conditions demonstrate some antiinflammatory effects of corticosteroids on gingival tissues, not necessarilya reduction in the rate of periodontal breakdown. ${ }^{11}$

Animal studies have provided some insightinto the relationship among stress, cortisol productionand periodontal breakdown. ${ }^{13}$ Rats that showed a low response to stress developedsignificantly less periodontal breakdown than thosethat showed a high 


\begin{tabular}{|l|l|}
\hline \multicolumn{1}{|c|}{ Target } & Effect \\
\hline Carbohydrate metabolism & Decreased uptake of glucose and increased gluconeogenesis, \\
& leading to an increased riskof diabetes \\
\hline Protein & especially in muscles, causing muscle wasting \\
\hline Bone & Osteoporosis \\
\hline Gastric mucosa & Increased risk of peptic ulceration \\
\hline Adrenal cortex & Suppression leading to an increased risk of an adrenocortical \\
& crisis \\
\hline Fat & Redistribution of body fat causing so-called moon faces and \\
\hline Skin & Buffalo hump \\
\hline Wound healing & Thinning of skin and an increased risk of acne \\
\hline Immune system & Impaired \\
\hline Blood vessels & Immunosuppression, increased risk of opportunistic infections \\
\hline
\end{tabular}

Table 3. List of unwanted effects of steroids

response.

The same group subsequently demonstrated a glucocorticoid receptor antagonist reduced periodontalbreakdown in ligature-induced periodontitisin rats. ${ }^{14}$ The authors concluded that hypothalamic-pituitary-adrenal axis hyper activationis one mechanism by which periodontal disease susceptibility may be increased.

Stress and salivary cortisol have been measured in anadult population suffering from periodontitis. ${ }^{15}$ Salivary cortisol levels were positively associated withan increase in psychological stress and in the extentand severity of periodontitis.

Corticosteroids are very potent and valuablegroup of drugs that are used to treat a variety ofmedical conditions. Their interest, in periodontalterms, is on their anti-inflammatory actions andwhether such actions can provide an insight into thepathogenesis of plaque-induced gingival inflammationand periodontal disease expression. Therefore,such drugs have been used as a pharmacological tooland do not have a place in the management ofperiodontal disease.

\section{Unwanted Effects Of Corticosteroids}

Steroidshavearange of unwanted effects, which arelisted 
in Table 3. Of particular concern to theperiodontist are the unwanted effects of steroidinducedosteoporosis and the risk of adrenocorticalsuppression. Table 3.

\section{Corticosteroid-Induced Osteoporosis}

Corticosteroids have a significant effect upon bonemetabolism. They increase bone resorption, inhibitbone formation, decrease the intestinal absorption ofcalcium ions and modify vitamin D metabolism. Thenet result is an increased risk of osteoporosis, whichis considered a risk factor for periodontal disease,especially an increased risk of tooth loss. ${ }^{16}$ It hasbeen estimated that $20-30 \%$ of patients on long-termsteroid therapy will develop osteoporosis. ${ }^{17}$ Therisk is higher in patients $>60$ years of age and also inwomen.

Corticosteroid-induced osteoporosis can bemanaged by dietary supplements of calcium and

vitamin D and also by bisphosphonates. Issuesrelating to the use of bisphosphonates and their unwantedeffects are discussed later.

\section{Conclusion}

This review has primarily focused on those immunosuppressant drugs that affect the inflammatory cascade and on the impact, if any of such medication on plaque-induced inflammation of the periodontal tissues and disease progression.Immunosuppressants do affect the response of gingival and periodontal tissues to bacterial plaque. They do not abolish the reaction of the tissues to plaque, but appear to dampen down inflammatoryreactions. The specific pharmacodynamics of immunosuppressants may provide further insight into the pathogenesis of periodontal inflammation and breakdown.

\section{References}

1. Page, R. C. \& Schroeder. H. E. Pathogenesis of inflammatory periodontal disease. Laboratory Investigations;1976, 33, 235 248.

2. Page, R. C. \& Schroeder, H. E. Current status of Ihe host response in chronic marginalgingivitis. Journal of Periodontology 1981; 52, 477-491.

3. AwsAlani\& Robin Seymour; Systemic medication and the inflammatory cascade, periodontology 2000, vol. 64, 2014, 198-210
4. Fu E, Hsieh YD, Nieh S, Wikesjo UM, Liu D. Effects of cyclosporine A on alveolar bone: an experimental study in therat. Journal of Periodontology 1999: 70: 189-194.

5. Gray DW. Mycophenolatemofetil for transplantation: new drug, old problems? Lancet 1995: 346: 390.

6. Rateitschak P, Hefti E $\mathrm{M}$ et al. Initial observation that cyclosporine-A induces gingival enlargement in man.Journal of Clinical Periodontology.1983;10:237-46.

7. MacGraw $\mathrm{T}$, Lam $\mathrm{S}$ et al. Cyclosporin induced gingival overgrowth: correlation with dental plaque scores, gingivitis scores and cyclosporine levels in serum and saliva. Oral Surgery Oral Med Oral Pathology 1987;64:293-7.

8. Peers SH, Smillie F, Elderfield AJ, Flower RJ. Glucocorticoidand non-glucocorticoid induction of lipocortins(annexins) 1 and 2 in rat peritoneal leucocytes in vivo.Br J Pharmacology 1993: 108: 66-72.

9. Leung DY, Bloom JW. Update on glucocorticoid action andresistance. J Allergy Clin Immunology 2003: 111: 3-22.

10. Newton R. Molecular mechanisms of glucocorticoid action:what is important? Thorax 2000: 55: 603-613.

11. Seymour RA, Heasman PA. Drugs and the periodontium.J ClinPeriodontol 1988: 15: 1-16.

12. Ezzat BA. Validity of prevention of glucocorticoidinducedalveolar bone loss in rat by either calcitonin or alendronateadministration. Arch Oral Biol 2010: 55: 788-796.

13. Breivik T, Opstad PK, Gjermo P, Thrane PS. Effects ofhypothalamic-pituitary-adrenal axis reactivity on periodontaltissue destruction in rats. Eur J Oral Sci 2000: 108:115-122.

14. Breivik T, Thrane PS, Gjermo P, Opstad PK. Glucocorticoidreceptor antagonist RU 486 treatment reduces periodontitisin Fischer 344 rats. J Periodontal Res 2000: 35: 285-290.

15. Hilgert JB, Hugo FN, Bandeira DR, Bozzetti MC. Stress,cortisol, and periodontitis in a population aged 50 yearsand over. J Dent Res 2006: 85: 324-328.

16. Nicopoulou-Karayianni K, Tzoutzoukos P, Mitsea A, KarayiannisA, Tsiklakis K, Jacobs R, Lindh C, van der Stelt P,Allen P, Graham J, Horner K, Devlin H, Pavitt S, Yuan J.Tooth loss and osteoporosis: the OSTEODENT Study. J ClinPeriodontol 2009: 36: 190-197.

17. Manelli F, Giustina A. Glucocorticoid-induced osteoporosis. Trends EndocrinolMetab 2000: 11: 79-85. 


\section{Address of Correspondence}

AnjushaBhadran

Pulari House

Mezhuveli P O Pathanamthitta( Dist)

Kerala (State) Pin : 689507

Contact no: 8301871757

Email : anjusha.bhadran91@gmail.com

\section{Authors:}

${ }^{1}$ II Year Post Graduate Student, Department of Periodontics, Sri Sankara Dental College, Akathumury

${ }^{2}$ Professor and Head of the Department, Sri Sankara Dental College Department of Periodontics, Akathumury

\section{How to cite this article :}

AnjushaBhadran, Seema G. Immunosuppressant Drugs: Role in Periodontium. Journal of Scientific Dentistry, 2016;6(2):6066

Source of Support : Nil, Conflicts of Interest : None declared 